\title{
Relationship of patient safety culture with factors influencing working environment such as working hours, the number of night shifts, and the number of days off among healthcare workers in Japan: a cross-sectional study
}

Ryosuke Hayashi ${ }^{1}$, Shigeru Fujita ${ }^{2}$, Shuhei lida ${ }^{3,4}$, Yoji Nagai ${ }^{5}$, Yoshiko Shimamori ${ }^{6}$ and Tomonori Hasegawa ${ }^{2^{*}}$

\begin{abstract}
Background: Patient safety culture is defined as a product of individual and group values, attitudes, perceptions, competencies, and patterns of behavior that determine the commitment to, and the style and proficiency of, an organization's health and safety management. Factors influencing healthcare workers' working environment such as working hours, the number of night shifts, and the number of days off may be associated with patient safety culture, and the association pattern may differ by profession. This study aimed to examine the relationship between patient safety culture and working environment.

Methods: Questionnaire surveys were conducted in 2015 and 2016. The first survey was conducted in hospitals in Japan to investigate their patient safety management system and activities and intention to participate in the second survey. The second survey was conducted in 40 hospitals; 100 healthcare workers from each hospital answered a questionnaire that was the Japanese version of the Hospital Survey on Patient Safety Culture for measuring patient safety culture. The relationship of patient safety culture with working hours in a week, the number of night shifts in a month, and the number of days off in a month was analyzed.

Results: Response rates for the first and second surveys were $22.4 \%$ (731/3270) and 94.2\% (3768/4000), respectively. Long working hours, numerous night shifts, and few days off were associated with low patient safety culture. Despite adjusting the working hours, the number of event reports increased with an increase in the number of night shifts. Physicians worked longer and had fewer days off than nurses. However, physicians had fewer composites of patient safety culture score related to working hours, the number of night shifts, and the number of days off than nurses.

(Continued on next page)
\end{abstract}

\footnotetext{
* Correspondence: health@med.toho-u.ac.jp

${ }^{2}$ Department of Social Medicine, Toho University School of Medicine, Tokyo, Japan

Full list of author information is available at the end of the article
}

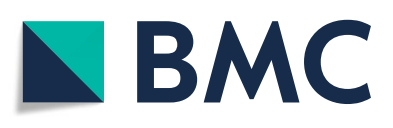

( ) The Author(s). 2020 Open Access This article is licensed under a Creative Commons Attribution 4.0 International License, which permits use, sharing, adaptation, distribution and reproduction in any medium or format, as long as you give appropriate credit to the original author(s) and the source, provide a link to the Creative Commons licence, and indicate if changes were made. The images or other third party material in this article are included in the article's Creative Commons licence, unless indicated otherwise in a credit line to the material. If material is not included in the article's Creative Commons licence and your intended use is not permitted by statutory regulation or exceeds the permitted use, you will need to obtain permission directly from the copyright holder. To view a copy of this licence, visit http://creativecommons.org/licenses/by/4.0/. The Creative Commons Public Domain Dedication waiver (http://creativecommons.org/publicdomain/zero/1.0/) applies to the data made available in this article, unless otherwise stated in a credit line to the data. 
(Continued from previous page)

Conclusions: This study suggested a possibility of improving the patient safety culture by managing the working environment of healthcare workers. High number of night shifts may lead to high number of event reports. Working hours, the number of night shifts, and the number of days off may differently influence patient safety culture in physicians and nurses.

Keywords: Patient safety, Safety management, Patient safety culture, Workload, Fatigue

\section{Background}

In a report published in 1999, the Institute of Medicine advocated establishment of a system that promotes patient safety and advised that medical institutions should develop a safety culture to prevent adverse events [1]. Patient safety culture is a product of individual and group values, attitudes, perceptions, competencies, and behavior patterns that determines the commitment as well as the style and proficiency of an organization's health and safety management [2]. Patient safety education and training $[3,4]$ as well as utilization of Team Strategies and Tools to Enhance Performance and Patient Safety [5] and root cause analysis [6] are useful for improving patient safety culture. We have reported that long working hours of nurses may deteriorate their patient safety culture [7], and two studies in China and a study in Korea have also reported same results [8-10]. Some studies have suggested that working environment deterioration of healthcare workers is associated with an increase in the number of event reports [11, 12]; however, few studies have examined the influence of working hours, the number of night shifts, and the number of days off on patient safety culture. Working environment associated with each profession may affect patient safety culture differently because each profession has different working environment characteristics [13-15].

This study aimed to investigate the relationship of patient safety culture of healthcare workers with their working hours, the number of night shifts, and the number of days off and to clarify the differences in this relationship depending on the profession.

\section{Methods}

In this study, two questionnaire surveys were conducted in 2015 and 2016. The first survey aimed to clarify hospitals' patient safety management system and activities as well as their intention to participate in the second survey. From August to September 2015, an anonymous nationwide mail survey was conducted in several hospitals in Japan. Among all hospitals in Japan, 25.0, 50.0, and $100 \%$ hospitals with < 100 beds, 100-299 beds, and $\geq 300$ beds, respectively, were randomly selected as target hospitals because patient safety management system or activities in each hospital may vary depending on the hospital size. University affiliated hospitals were excluded because they are obligated to assign full-time patient safety managers including a physician, a nurse, and a pharmacist, but others are not obligated to assign them. Respondents of the first survey were chief medical directors or patient safety managers in the target hospitals.

The second survey, conducted in 2016, aimed to measure patient safety culture of healthcare workers. Among the hospitals that expressed their intention to participate in the second survey, acute care hospitals with $\geq 300$ beds using an electronic medical record system were selected as target hospitals. The questionnaires were distributed to 100 healthcare workers in each target hospital. The healthcare workers comprised 12 physicians, 66 nurses, 16 technicians/therapists, and 6 pharmacists. The number of professions was determined according to the number of professions in the national statistics of healthcare workers in Japanese hospitals [16]. If the number of those professions was insufficient, each hospital was permitted to include other professions, such as a dietitian, cook, or clerk. A total of 100 healthcare workers were included; they were selected by patient safety managers in each hospital using the purposive selection method. Random sampling was not used to reduce the effort of counterpart at each hospital. To avoid bias in selecting respondents with a specific patient safety culture, patient safety managers were requested to distribute the questionnaires to healthcare workers without bias in the number of years of experience, position, and involvement in patient safety activities and to distribute them to nurses in multiple wards, including both internal medicine and surgical wards.

\section{Measurement}

The first survey questionnaire included questions on the functions of the hospital, the number of beds, and the assignment status of patient safety managers and the intention to participate in the second survey.

The second survey questionnaire included questions on respondents' working hours in a week, the number of night shifts in a month, the number of days off in a month, and patient safety culture. As for the response options, Likert scales were used for those questions. The patient safety culture was measured by the Japanese version of the Hospital Survey on Patient Safety Culture developed by the United States Agency for Healthcare Research and Quality [2,17]. This survey comprises 44 questions and can calculate scores for 12 composites 
related to patient safety culture as well as scores for patient safety grade and number of events reported in two items. For those questions, Likert scales with 5-point response options for agreement (1: Strongly disagree to 5: Strongly agree), frequency (1: Never to 5: Always), Patient Safety Grade (1: Failing to 5: Excellent), and number of events reported (from 1: No events to 5: 21 events or more) were used. The 12 composite scores were calculated according to a guideline of the Agency for Healthcare Research and Quality [18]. Proportion of positive responses for those questions is calculated as a composite score. The second survey questionnaire is shown in Additional file 2.

A higher score means a better patient safety culture. Regarding patient safety grade, the respondents were classified into two groups: those who answered "very good" or "good" and the others. Regarding the number of events reported, the respondents were also classified into two groups: those who reported one or more adverse events or near misses and the others. Regarding the working hours in a week, the number of night shifts, and the number of days off, the respondents were classified into three groups as shown in Table 1.

\section{Data analysis}

Patient safety culture scores for all respondents were calculated, and the relationship of these scores with working hours in a week, the number of night shifts in a month, and the number of days off in a month was analyzed.

The relationship of composite scores with working hours in a week, the number of night shifts in a month, and the number of days off in a month was analyzed using Spearman's $\rho$. The relationship of the patient safety grade and the number of events reported with working hours in a week, the number of night shifts in a month, and the number of days off in a month was analyzed using Cramer's V.

To analyze the relationship of patient safety culture scores with working hours in a week, the number of night shifts in a month, and the number of days off in a month, a generalized linear mixed model (GLMM) was used. The GLMM analysis was performed for all respondents, for physicians, and for nurses. Furthermore, regarding GLMM, the targets were patient safety culture scores; the fixed effects were working hours in a week, the number of night shifts in a month, and the number of days off in a month; and the random effect was the difference of hospitals. In the analysis of all respondents, the results were adjusted by profession and the years of experience. In the analysis of each profession, the results were adjusted by the years of experience. In the analysis for physicians, the working hours in a week and the

Table 1 Characteristics of respondents

\begin{tabular}{|c|c|c|c|c|c|c|c|c|c|}
\hline & & \multicolumn{2}{|c|}{ All respondents } & \multicolumn{2}{|c|}{ Nurses } & \multicolumn{2}{|c|}{ Physicians } & \multicolumn{2}{|c|}{ Others } \\
\hline & & $n$ & (\%) & $n$ & $(\%)$ & $n$ & (\%) & $n$ & (\%) \\
\hline \multirow[t]{7}{*}{ Years of experience } & $<1$ & 203 & (5.4) & 143 & (6.0) & 13 & (3.5) & 47 & $(4.6)$ \\
\hline & $1-5$ & 986 & $(26.2)$ & 680 & $(28.5)$ & 66 & (17.9) & 240 & (23.7) \\
\hline & $6-10$ & 631 & $(16.7)$ & 399 & $(16.7)$ & 51 & $(13.9)$ & 181 & (17.9) \\
\hline & $11-15$ & 551 & (14.6) & 358 & $(15.0)$ & 48 & (13.0) & 145 & $(14.3)$ \\
\hline & $16-20$ & 467 & $(12.4)$ & 296 & $(12.4)$ & 42 & $(11.4)$ & 129 & $(12.7)$ \\
\hline & $\geq 21$ & 802 & $(21.3)$ & 428 & $(17.9)$ & 137 & $(37.2)$ & 237 & (23.4) \\
\hline & No answer & 128 & (3.4) & 83 & (3.5) & 11 & (3.0) & 34 & (3.4) \\
\hline \multirow[t]{4}{*}{ Working hours in a week } & $<40$ & 1154 & (30.6) & 872 & $(36.5)$ & 13 & (3.5) & 269 & (26.6) \\
\hline & $40-60$ & 2145 & $(56.9)$ & 1392 & $(58.3)$ & 191 & $(51.9)$ & 652 & $(64.4)$ \\
\hline & $\geq 60$ & 365 & $(9.7)$ & 130 & (5.4) & 162 & $(44.0)$ & 73 & $(7.2)$ \\
\hline & No answer & 104 & $(2.8)$ & 83 & (3.5) & 2 & $(0.5)$ & 19 & $(1.9)$ \\
\hline \multirow[t]{4}{*}{ Number of night shifts in a month } & 0 & 764 & $(20.3)$ & 243 & $(10.2)$ & 86 & $(23.4)$ & 435 & $(42.9)$ \\
\hline & $1-4$ & 1628 & $(43.2)$ & 888 & $(37.2)$ & 225 & $(61.1)$ & 515 & (50.8) \\
\hline & $\geq 5$ & 1347 & $(35.7)$ & 1239 & $(51.9)$ & 55 & $(14.9)$ & 53 & $(5.2)$ \\
\hline & No answer & 29 & $(0.8)$ & 17 & $(0.7)$ & 2 & $(0.5)$ & 10 & $(1.0)$ \\
\hline \multirow[t]{4}{*}{ Number of days off in a month } & $\geq 10$ & 1049 & $(27.8)$ & 875 & $(36.7)$ & 4 & $(1.1)$ & 170 & (16.8) \\
\hline & $7-9$ & 2137 & $(56.7)$ & 1359 & $(56.9)$ & 106 & $(28.8)$ & 672 & $(66.3)$ \\
\hline & $<7$ & 487 & $(12.9)$ & 83 & (3.5) & 253 & $(68.8)$ & 151 & (14.9) \\
\hline & No answer & 95 & $(2.5)$ & 70 & (2.9) & 5 & $(1.4)$ & 20 & (2.0) \\
\hline Total & & 3768 & (100.0) & 2387 & (100.0) & 368 & (100.0) & 1013 & (100.0) \\
\hline
\end{tabular}


number of days off in a month were classified into two groups because the sample size of light workload group was too small to analyze. $P<0.05$ indicated significance. Missing data were excluded from the analysis. IBM SPSS Statistics version 19 was used for statistical analysis.

\section{Ethical considerations}

This study was approved by the Ethics Committee of the Toho University School of Medicine (No. 27045).

\section{Results}

The response rate for the first survey was 22.4\% (731/ $3270)$. The response rates varied by hospital size: that in hospitals with 300 beds or more was $24.1 \%$, that in hospitals with 100-299 beds was $21.4 \%$, and that in hospitals with less than 100 beds was $13.9 \%$. Among the participating hospitals, 205 responded that they intended to participate in the second survey; however, only 81 hospitals fulfilled the criteria for the second survey. For these 81 hospitals, we confirmed the intention to participate in the second survey again because the second

Table 2 Patient safety culture scores in all respondents

\begin{tabular}{|c|c|c|c|c|c|c|c|c|c|c|c|c|c|}
\hline & \multirow[t]{2}{*}{ All respondents } & \multicolumn{4}{|c|}{ Working hours in a week } & \multicolumn{4}{|c|}{ Number of night shifts in a month } & \multicolumn{4}{|c|}{ Number of days off in a month } \\
\hline & & $<40$ & $40-60$ & $\geq 60$ & Spearman's $\rho$ & 0 & $1-4$ & $\geq 5$ & Spearman's $\rho$ & $\geq 10$ & $7-9$ & $<7$ & Spearman's $\rho$ \\
\hline $\begin{array}{l}\text { (Number of } \\
\text { respondents) }\end{array}$ & (3768) & $(1154)$ & $(2145)$ & $(365)$ & & $(764)$ & $(1628)$ & $(1347)$ & & $(1049)$ & $(2137)$ & $(487)$ & \\
\hline $\begin{array}{l}\text { Teamwork within } \\
\text { units }\end{array}$ & 0.76 & 0.79 & 0.75 & 0.73 & $-0.07^{a}$ & 0.76 & 0.76 & 0.76 & 0.01 & 0.80 & 0.75 & 0.72 & $-0.08^{a}$ \\
\hline $\begin{array}{l}\text { Supervisor or } \\
\text { manager } \\
\text { expectations } \\
\text { and actions } \\
\text { promoting } \\
\text { patient safety }\end{array}$ & 0.70 & 0.72 & 0.69 & 0.68 & $-0.06^{\mathrm{a}}$ & 0.68 & 0.71 & 0.70 & 0.03 & 0.73 & 0.69 & 0.66 & $-0.07^{a}$ \\
\hline $\begin{array}{l}\text { Organizational } \\
\text { learning-continuous } \\
\text { improvement }\end{array}$ & 0.58 & 0.61 & 0.57 & 0.57 & $-0.05^{a}$ & 0.61 & 0.59 & 0.56 & $-0.05^{a}$ & 0.61 & 0.57 & 0.55 & $-0.07^{a}$ \\
\hline $\begin{array}{l}\text { Management } \\
\text { support for } \\
\text { patient safety }\end{array}$ & 0.61 & 0.64 & 0.60 & 0.54 & $-0.08^{a}$ & 0.62 & 0.62 & 0.58 & $-0.04^{a}$ & 0.65 & 0.60 & 0.56 & $-0.08^{a}$ \\
\hline $\begin{array}{l}\text { Overall perceptions } \\
\text { of patient safety }\end{array}$ & 0.59 & 0.61 & 0.58 & 0.54 & $-0.06^{\mathrm{a}}$ & 0.63 & 0.60 & 0.55 & $-0.09^{a}$ & 0.59 & 0.59 & 0.58 & 0.00 \\
\hline $\begin{array}{l}\text { Feedback and } \\
\text { communication } \\
\text { about error }\end{array}$ & 0.66 & 0.70 & 0.66 & 0.53 & $-0.11^{\mathrm{a}}$ & 0.65 & 0.64 & 0.68 & $0.05^{b}$ & 0.72 & 0.66 & 0.52 & $-0.15^{a}$ \\
\hline $\begin{array}{l}\text { Communication } \\
\text { openness }\end{array}$ & 0.57 & 0.59 & 0.57 & 0.56 & -0.03 & 0.58 & 0.58 & 0.56 & -0.02 & 0.60 & 0.57 & 0.56 & $-0.04^{b}$ \\
\hline $\begin{array}{l}\text { Frequency of } \\
\text { events reported }\end{array}$ & 0.71 & 0.71 & 0.72 & 0.65 & -0.02 & 0.70 & 0.71 & 0.72 & 0.02 & 0.72 & 0.71 & 0.64 & $-0.04^{b}$ \\
\hline $\begin{array}{l}\text { Teamwork across } \\
\text { units }\end{array}$ & 0.49 & 0.51 & 0.48 & 0.51 & -0.03 & 0.50 & 0.51 & 0.47 & $-0.05^{a}$ & 0.51 & 0.48 & 0.52 & 0.00 \\
\hline Staffing & 0.42 & 0.46 & 0.41 & 0.37 & $-0.09^{a}$ & 0.46 & 0.45 & 0.37 & $-0.14^{a}$ & 0.42 & 0.43 & 0.41 & 0.00 \\
\hline $\begin{array}{l}\text { Handoffs and } \\
\text { transitions }\end{array}$ & 0.35 & 0.37 & 0.35 & 0.28 & $-0.07^{a}$ & 0.36 & 0.36 & 0.34 & -0.01 & 0.37 & 0.34 & 0.32 & $-0.05^{a}$ \\
\hline $\begin{array}{l}\text { Nonpunitive } \\
\text { response to errors }\end{array}$ & 0.51 & 0.52 & 0.50 & 0.49 & -0.03 & 0.55 & 0.54 & 0.45 & $-0.11^{\mathrm{a}}$ & 0.49 & 0.51 & 0.52 & 0.02 \\
\hline $\begin{array}{l}\text { Proportion of } \\
\text { respondents who } \\
\text { rated the patient } \\
\text { safety grade as } \\
\text { "very good" or } \\
\text { "good" }\end{array}$ & 0.48 & 0.52 & 0.47 & 0.43 & $0.06^{a, c}$ & 0.50 & 0.50 & 0.44 & $0.06^{a, c}$ & 0.47 & 0.48 & 0.50 & $0.02^{c}$ \\
\hline $\begin{array}{l}\text { Proportion of } \\
\text { respondents who } \\
\text { reported one or } \\
\text { more events }\end{array}$ & 0.79 & 0.79 & 0.80 & 0.70 & $0.07^{a, c}$ & 0.60 & 0.79 & 0.90 & $0.26^{\mathrm{a}, \mathrm{c}}$ & 0.84 & 0.80 & 0.64 & $0.16^{a, c}$ \\
\hline
\end{tabular}


survey was conducted approximately 1 year after the first survey, and consequently, 40 hospitals participated.

The second survey was conducted in these 40 hospitals in which 9 are located in urban areas and others are located in rural areas. Among them, 14 hospitals have 300-399 beds, 13 hospitals have 400-499 beds, and 13 hospitals have 500 beds or more. The response rate for the second survey was $94.2 \%$ (3768/4000). Among the respondents, $66.7 \%$ were nurses and nursing aids, 9.8\% were physicians, $6.1 \%$ were pharmacists, $15.4 \%$ were therapists and technicians, and $1.9 \%$ were the others. The proportion of each profession corresponded to the number of distributions by profession.

Characteristics of the respondents are shown in Table 1. The proportion of physicians who worked $\geq 60 \mathrm{~h}$ in a week was higher than that of nurses $(44.3 \%$ vs. $5.6 \%, P<0.01)$; furthermore, the proportion of physicians who had less than 7 days off in a month was also higher than that of nurses $(69.7 \%$ vs. $3.6 \%, P<0.01)$.

Table 2 and Table A1 shown in Additional file 1 presents the mean patient safety culture scores and their correlation with working hours, the number of night shifts, and the number of days off. The scores of eight composites tended to decrease as the working hours increased although the correlation coefficients represent small associations. Similarly, the scores of seven composites tended to decrease as the number of night shifts increased. Furthermore, the scores of eight composites tended to decrease as the number of days off decreased.

The GLMM analysis results for all respondents are shown in Table 3. Patient safety culture composite scores tended to decrease as working hours and the number of night shifts increased or the number of days off decreased. Tables 4 and 5 present the GLMM analysis results for nurses and physicians, respectively. Regarding nurses, working hours were associated with the scores of seven composites and patient safety grade, the number of night shifts was associated with the scores of three composites and the number of events reported, and the number of days off was associated with the scores of seven composites. Regarding physicians, working hours were associated with the scores of two composites, the number of night shifts was associated with the scores of three composites and patient safety grade, and the number of days off was associated with the score of one composite.

Table 3 Relationship between the working environment and patient safety culture scores in all respondents ${ }^{\mathrm{a}}$

\begin{tabular}{|c|c|c|c|c|c|c|c|c|c|c|c|}
\hline \multirow[t]{4}{*}{ Response variables } & \multirow[b]{4}{*}{ (n) } & \multicolumn{9}{|c|}{ Explanatory variables } & \multirow[t]{4}{*}{ AICC } \\
\hline & & \multicolumn{3}{|c|}{ Working hours in a week } & \multicolumn{3}{|c|}{$\begin{array}{l}\text { Number of night shifts } \\
\text { in a month }\end{array}$} & \multicolumn{3}{|c|}{$\begin{array}{l}\text { Number of days off in } \\
\text { a month }\end{array}$} & \\
\hline & & $<40$ & $40-60$ & $\geq 60$ & 0 & $1-4$ & $\geq 5$ & $\geq 10$ & $7-9$ & $<7$ & \\
\hline & & $(1154)$ & $(2145)$ & $(365)$ & (764) & $(1628)$ & $(1347)$ & (1049) & (2137) & $(487)$ & \\
\hline Teamwork within units & Coefficient & 0.00 & $-0.04^{b}$ & $-0.08^{c}$ & 0.00 & $-0.03^{c}$ & $-0.06^{c}$ & 0.00 & $-0.04^{c}$ & $-0.10^{c}$ & 1738 \\
\hline $\begin{array}{l}\text { Supervisor or manager expectations } \\
\text { and actions promoting patient safety }\end{array}$ & & 0.00 & $-0.02^{c}$ & -0.01 & 0.00 & 0.00 & -0.03 & 0.00 & $-0.03^{b}$ & $-0.06^{\mathrm{b}}$ & 1345 \\
\hline $\begin{array}{l}\text { Organizational learning-continuous } \\
\text { improvement }\end{array}$ & & 0.00 & $-0.03^{c}$ & 0.00 & 0.00 & $-0.04^{c}$ & $-0.08^{\mathrm{c}}$ & 0.00 & $-0.03^{c}$ & -0.02 & 2286 \\
\hline Management support for patient safety & & 0.00 & $-0.03^{c}$ & $-0.11^{c}$ & 0.00 & -0.01 & -0.06 & 0.00 & $-0.05^{b}$ & $-0.08^{b}$ & 2640 \\
\hline Overall perceptions of patient safety & & 0.00 & $-0.04^{b}$ & $-0.09^{b}$ & 0.00 & $-0.04^{c}$ & $-0.07^{c}$ & 0.00 & -0.01 & -0.03 & 2268 \\
\hline Feedback and communication about error & & 0.00 & -0.01 & $-0.05^{c}$ & 0.00 & $-0.04^{c}$ & $-0.05^{b}$ & 0.00 & $-0.04^{b}$ & $-0.07^{b}$ & 2599 \\
\hline Communication openness & & 0.00 & -0.02 & -0.03 & 0.00 & $-0.04^{c}$ & $-0.07^{b}$ & 0.00 & $-0.03^{c}$ & $-0.07^{\mathrm{b}}$ & 2764 \\
\hline Frequency of events reported & & 0.00 & 0.02 & 0.02 & 0.00 & -0.02 & -0.02 & 0.00 & -0.01 & -0.02 & 2903 \\
\hline Teamwork across units & & 0.00 & $-0.05^{b}$ & $-0.05^{c}$ & 0.00 & -0.01 & -0.03 & 0.00 & $-0.04^{c}$ & $-0.06^{c}$ & 2404 \\
\hline Staffing & & 0.00 & $-0.05^{b}$ & $-0.12^{b}$ & 0.00 & 0.02 & $-0.04^{b}$ & 0.00 & -0.02 & $-0.09^{b}$ & 908 \\
\hline Handoffs and transitions & & 0.00 & -0.02 & $-0.08^{b}$ & 0.00 & 0.01 & 0.00 & 0.00 & -0.03 & $-0.05^{c}$ & 2282 \\
\hline Nonpunitive response to errors & & 0.00 & $-0.04^{c}$ & $-0.08^{b}$ & 0.00 & -0.01 & $-0.08^{b}$ & 0.00 & -0.01 & $-0.08^{b}$ & 2967 \\
\hline $\begin{array}{l}\text { Respondents who rated patient } \\
\text { safety grade as "very good" or } \\
\text { "good" (vs. others) }\end{array}$ & $\mathrm{aOR}$ & 1.00 & $0.73^{\mathrm{b}}$ & $0.56^{\mathrm{b}}$ & 1.00 & 0.88 & $0.76^{c}$ & 1.00 & 1.02 & 1.05 & 14,247 \\
\hline $\begin{array}{l}\text { Respondents who reported one } \\
\text { or more events (vs. none) }\end{array}$ & & 1.00 & $1.33^{c}$ & 1.29 & 1.00 & $1.72^{\mathrm{b}}$ & $2.66^{\mathrm{b}}$ & 1.00 & 0.96 & 0.90 & 17,215 \\
\hline
\end{tabular}

AICC Akaike's Information Criterion Correction, aOR: adjusted Odds Ratio, (n): Number of respondents

${ }^{a}$ Results of the generalized linear mixed model using working hours, the number of night shifts, and the number of days off as explanatory variables

${ }^{\mathrm{b}} P<0.01$

${ }^{c} P<0.05$ 
Table 4 Relationship between the working environment and patient safety culture scores in nurses ${ }^{\mathrm{a}}$

\begin{tabular}{|c|c|c|c|c|c|c|c|c|c|c|c|}
\hline \multirow[t]{4}{*}{ Response variables } & \multirow[b]{4}{*}{ (n) } & \multicolumn{9}{|c|}{ Explanatory variables } & \multirow[t]{4}{*}{ AICC } \\
\hline & & \multicolumn{3}{|c|}{$\begin{array}{l}\text { Working hours in a } \\
\text { week }\end{array}$} & \multicolumn{3}{|c|}{$\begin{array}{l}\text { Number of night shifts } \\
\text { in a month }\end{array}$} & \multicolumn{3}{|c|}{$\begin{array}{l}\text { Number of days off in } \\
\text { a month }\end{array}$} & \\
\hline & & $<40$ & $40-60$ & $\geq 60$ & 0 & $1-4$ & $\geq 5$ & $\geq 10$ & $7-9$ & $<7$ & \\
\hline & & $(872)$ & $(1392)$ & $(130)$ & (243) & (888) & (1239) & $(875)$ & (1359) & (83) & \\
\hline Teamwork within units & Coefficient & 0.00 & $-0.04^{b}$ & $-0.07^{c}$ & 0.00 & 0.02 & -0.03 & 0.00 & $-0.04^{b}$ & $-0.07^{c}$ & 932 \\
\hline $\begin{array}{l}\text { Supervisor or manager expectations and } \\
\text { actions promoting patient safety }\end{array}$ & & 0.00 & -0.01 & 0.00 & 0.00 & 0.00 & -0.03 & 0.00 & $-0.05^{b}$ & $-0.12^{b}$ & 721 \\
\hline Organizational learning-continuous improvement & & 0.00 & $-0.04^{c}$ & 0.02 & 0.00 & -0.04 & $-0.09^{b}$ & 0.00 & $-0.03^{c}$ & -0.02 & 1444 \\
\hline Management support for patient safety & & 0.00 & -0.02 & -0.05 & 0.00 & 0.00 & -0.05 & 0.00 & $-0.05^{\mathrm{b}}$ & -0.06 & 1632 \\
\hline Overall perceptions of patient safety & & 0.00 & -0.03 & $-0.11^{b}$ & 0.00 & $-0.05^{c}$ & $-0.08^{b}$ & 0.00 & -0.01 & -0.03 & 1401 \\
\hline Feedback and communication about error & & 0.00 & -0.02 & -0.04 & 0.00 & -0.04 & -0.04 & 0.00 & -0.02 & -0.05 & 1468 \\
\hline Communication openness & & 0.00 & -0.02 & 0.01 & 0.00 & -0.02 & -0.04 & 0.00 & -0.03 & -0.06 & 1735 \\
\hline Frequency of events reported & & 0.00 & 0.02 & 0.02 & 0.00 & -0.01 & -0.01 & 0.00 & -0.01 & 0.01 & 1721 \\
\hline Teamwork across units & & 0.00 & -0.02 & $-0.07^{c}$ & 0.00 & -0.01 & -0.05 & 0.00 & $-0.04^{b}$ & -0.06 & 1469 \\
\hline Staffing & & 0.00 & $-0.05^{b}$ & $-0.14^{\mathrm{b}}$ & 0.00 & -0.01 & $-0.06^{b}$ & 0.00 & -0.02 & $-0.07^{c}$ & 458 \\
\hline Handoffs and transitions & & 0.00 & 0.00 & $-0.08^{c}$ & 0.00 & 0.01 & -0.01 & 0.00 & -0.02 & -0.05 & 1429 \\
\hline Nonpunitive response to errors & & 0.00 & -0.03 & $-0.09^{b}$ & 0.00 & 0.05 & -0.04 & 0.00 & -0.02 & $-0.12^{\mathrm{b}}$ & 1829 \\
\hline $\begin{array}{l}\text { Respondents who rated patient safety grade } \\
\text { as "very good" or "good" (vs. others) }\end{array}$ & $\mathrm{aOR}$ & 1.00 & $0.73^{b}$ & 0.69 & 1.00 & 0.87 & 0.73 & 1.00 & 1.05 & 1.09 & 8877 \\
\hline $\begin{array}{l}\text { Respondents who reported one or more } \\
\text { events (vs. none) }\end{array}$ & & 1.00 & 1.02 & 1.08 & 1.00 & $2.28^{b}$ & $3.58^{b}$ & 1.00 & 1.13 & 1.00 & 11,529 \\
\hline
\end{tabular}

AICC Akaike's Information Criterion Correction, $a O R$ : adjusted Odds Ratio, $(n)$ Number of respondents

${ }^{a}$ Results of the generalized linear mixed model using working hours, the number of night shifts and the number of days off as explanatory variables ${ }^{\mathrm{b}} P<0.01$

${ }^{c} P<0.05$

\section{Discussion}

The study results suggest that not only working hours but also the number of night shifts and days off of healthcare workers are related to patient safety culture. Therefore, these factors should be managed cautiously to improve patient safety culture.

Previous studies in China reported that long working hours may deteriorate patient safety culture of healthcare workers $[8,9]$. In Korea, dental hygienists who worked more than $40 \mathrm{~h}$ in a week showed lower scores in most composites excepting "organizational learning-continuous improvement" than those who worked $40 \mathrm{~h}$ or less in a week [10]. Regarding the relationship of working hours with patient safety culture, previous studies show same tendency with our results [7-10], but no study shows the relationship of number of night shifts and days off with patient safety culture.

Regarding the analysis for all respondents, the number of event reports increased as the number of night shifts increased, despite adjusting working hours. Considering that the composite score of "frequency of events reported" was not related to working hours and the number of night shifts, the increase in the number of night shifts could lead to an increase in adverse events or near misses.

Physicians' workload was higher than that of nurses; however, the number of composites associated with working hours, the number of night shifts, and the number of days off for physicians was fewer than that for nurses. This difference between physicians and nurses suggests that different mechanisms or factors should be considered for determining the relationship between workload and patient safety culture of these professions. Heavy workload increases the occupational stress, anxiety, and depression among healthcare workers [19]. In addition, the increasing occupational stress, anxiety, and depression increase the number of adverse events and near misses [11, 12, 20, 21]. Patient safety culture may be similarly affected by occupational stress, anxiety, and depression, which are, in turn, influenced by working hours, the number of night shifts, and the number of days off. Physician's stress response for occupational stress was reportedly weaker than that of nurses because physicians got more supports from their supervisors and colleagues than nurses, and physicians have more discretionary power than nurses [22]. In addition, nurses tend to have stress responses because they spend a lot of times for direct interaction or contact with patients, and work physically demanding [22]. In our study, physicians' workload was higher than that of nurses, but the stress response of physicians may have been weaker than that of nurses. Consequently, composites associated with 
Table 5 Relationship between the working environment and patient safety culture scores in physicians ${ }^{\mathrm{a}}$

\begin{tabular}{|c|c|c|c|c|c|c|c|c|c|}
\hline \multirow[t]{4}{*}{ Response variables } & \multirow[b]{4}{*}{ (n) } & \multicolumn{7}{|c|}{ Explanatory variables } & \multirow[t]{4}{*}{$\mathrm{AICC}$} \\
\hline & & \multicolumn{2}{|c|}{$\begin{array}{l}\text { Working hours } \\
\text { in a week }\end{array}$} & \multicolumn{3}{|c|}{$\begin{array}{l}\text { Number of night shifts } \\
\text { in a month }\end{array}$} & \multicolumn{2}{|c|}{$\begin{array}{l}\text { Number of days } \\
\text { off in a month }\end{array}$} & \\
\hline & & $<60$ & $\geq 60$ & 0 & $1-4$ & $\geq 5$ & $\geq 7$ & $\leq 6$ & \\
\hline & & $(204)$ & $(162)$ & (86) & $(225)$ & (55) & $(110)$ & $(253)$ & \\
\hline Teamwork within units & Coefficient & 0.00 & $-0.08^{b}$ & 0.00 & $-0.11^{c}$ & -0.07 & 0.00 & -0.05 & 140 \\
\hline $\begin{array}{l}\text { Supervisor or manager expectations and actions } \\
\text { promoting patient safety }\end{array}$ & & 0.00 & 0.01 & 0.00 & 0.01 & -0.03 & 0.00 & 0.03 & 203 \\
\hline Organizational learning-continuous improvement & & 0.00 & -0.02 & 0.00 & -0.05 & -0.08 & 0.00 & -0.02 & 259 \\
\hline Management support for patient safety & & 0.00 & $-0.13^{c}$ & 0.00 & -0.04 & -0.06 & 0.00 & -0.07 & 301 \\
\hline Overall perceptions of patient safety & & 0.00 & -0.04 & 0.00 & -0.04 & -0.03 & 0.00 & -0.06 & 244 \\
\hline Feedback and communication about error & & 0.00 & -0.07 & 0.00 & $-0.15^{\mathrm{c}}$ & $-0.23^{c}$ & 0.00 & -0.05 & 339 \\
\hline Communication openness & & 0.00 & -0.05 & 0.00 & -0.09 & -0.13 & 0.00 & -0.01 & 316 \\
\hline Frequency of events reported & & 0.00 & 0.02 & 0.00 & $-0.14^{b}$ & $-0.23^{c}$ & 0.00 & -0.05 & 377 \\
\hline Teamwork across units & & 0.00 & 0.02 & 0.00 & -0.03 & -0.03 & 0.00 & 0.02 & 301 \\
\hline Staffing & & 0.00 & -0.06 & 0.00 & 0.07 & 0.05 & 0.00 & $-0.12^{c}$ & 137 \\
\hline Handoffs and transitions & & 0.00 & -0.05 & 0.00 & 0.08 & 0.02 & 0.00 & -0.06 & 265 \\
\hline Nonpunitive response to errors & & 0.00 & -0.02 & 0.00 & 0.02 & -0.02 & 0.00 & -0.03 & 309 \\
\hline $\begin{array}{l}\text { Respondents who rated patient safety grade as } \\
\text { "very good" or "good" (vs. others) }\end{array}$ & $\mathrm{aOR}$ & 1.00 & $0.55^{\mathrm{b}}$ & 1.00 & 0.57 & $0.40^{\mathrm{b}}$ & 1.00 & 0.75 & 1464 \\
\hline Respondents who reported one or more events (vs. none) & & 1.00 & 1.45 & 1.00 & 1.38 & 1.76 & 1.00 & 1.44 & 1500 \\
\hline
\end{tabular}

working hours, the number of night shifts, and the number of days off in physicians may be less than those in nurses.

Regarding nurses, working hours, the number of night shifts, and the number of days off were not associated with the scores in two composites: "feedback and communication about error" and "frequency of events reported." The attitudes of nurses toward event reporting and error discussion might be affected by other factors such as the implementation of a simple and easy event reporting system and good teamwork within units [2326]. Meanwhile, physicians' scores for these two composites decreased as the number of night shifts increased. Physicians might stop reporting events and discussing about errors when the number of night shifts increases; however, the reason for this is unknown. Hence, the underlying reasons need to be determined in the future.

\section{Limitations of this study}

This was a cross-sectional study; thus, the causal relationship remains unclear. The response rate for the first survey was not high especially in small hospitals, and the situations in small hospitals may not be fully reflected in our results because acute care hospitals with $<300$ beds or long-term care hospitals were not included in the second survey. Agency for Healthcare Research and Quality reported that patient safety culture scores in small hospitals were higher than those in large hospitals [2]. The impact of the working environment in small hospitals on the patient safety culture can be different from that in large hospitals. In addition, the responding facilities could be the hospitals with a good patient safety culture. In the second survey, patient safety managers in each hospital selected the respondents using purposive selection method; these selected respondents might already have been highly aware of patient safety. It was unknown whether the respondents were selected without bias at each hospital. The next study may need to use random sampling to select healthcare workers at each hospital. However, the influences of working hours, the number of night shifts, and the number of days off on patient safety culture might be similar among healthcare workers with better or worse patient safety culture. In this study, each hospital was permitted to include other professions, such as a dietitian, cook, or clerk if the number of designated professions was insufficient. However, those respondents accounted for only $0.9 \%$, and those respondents may have little effect on the results. This study did not aim to figure out patient safety culture of the target 
population but to determine the relationship of patient safety culture with working hours, the number of night shifts, and the number of days off; the limitation of representativeness in our study could have minimal effects on the results. Regarding the GLMMs, up to $9.1 \%$ of the data was excluded from the analysis due to the rate of missing answers to questions, and the missing data may have little effect on the results.

\section{Conclusion}

This study suggested a possibility of improving the patient safety culture by managing the working environment of healthcare workers. Proper management of the number of night shifts and days off as well as working hours of healthcare workers might improve patient safety culture. An increase in the number of night shifts might lead to an increase in the reports of adverse events and near misses. Working hours, the number of night shifts, and the number of days off differently influence patient safety culture of physicians and nurses.

\section{Supplementary information}

Supplementary information accompanies this paper at https://doi.org/10. 1186/s12913-020-05114-8.

Additional file 1. Table A1. Patient Safety Culture Scores and SD in all Respondents.

Additional file 2. A survey for working environment and patient safety culture.

\section{Abbreviations}

GLMM: generalized linear mixed model; AICC: Akaike's Information Criterion Correction; aOR: adjusted Odds Ratio; SD: Standard Deviation

\section{Acknowledgements}

We would like to thank the hospitals that have contributed to the study by filling in the questionnaires.

\section{Author's contributions}

$\mathrm{RH}$ performed the statistical analysis and prepared the draft. SF, SI, YN and YS acquired the data, participated in the design of the study and performed the statistical analysis. TH made substantial contributions to the conception, design of the work, acquisition, analysis and interpretation of data. TH also revised this manuscript, and managed the whole research processes. All authors read and approved the final manuscript.

\section{Funding}

This study was supported by a Health, Labour and Welfare Sciences Research Grant (grant number: H27-iryo-ippan-007). This funding institution did not have any other role in the design of this trial, in the collection or interpretation of the data, in the preparation of the manuscript.

\section{Availability of data and materials}

All data supporting our findings were presented within the manuscript.

\section{Ethics approval and consent to participate}

This research project including the informed consent procedure for participation was approved by the Ethics Committee of the Toho University School of Medicine (No. 27045). We conducted an anonymous selfadministered questionnaire survey, and it was considered that consent to participation in the study was obtained by answering the questionnaire.

\section{Consent for publication}

The Ethics Committee of the Toho University School of Medicine approved the informed consent procedure for publication (No. 27045). The questionnaire stated that the data will be published, and it was considered that consent for publication was obtained by answering the questionnaire.

\section{Competing interests}

The authors declare that they have no competing interests.

\section{Author details}

${ }^{1}$ Toho University Graduate School of Medicine, Tokyo, Japan. ${ }^{2}$ Department of Social Medicine, Toho University School of Medicine, Tokyo, Japan. ${ }^{3}$ Nerima General Hospital, Tokyo, Japan. ${ }^{4}$ Institute of Healthcare Quality Improvement, Tokyo, Japan. ${ }^{5}$ Hitachinaka General Hospital, Ibaraki, Japan. ${ }^{6}$ Department of Common Fundamental Nursing, Iwate Medical University School of Nursing, Iwate, Japan.

Received: 15 November 2019 Accepted: 17 March 2020

Published online: 15 April 2020

\section{References}

1. Institute of Medicine (US) Committee on Quality of Health Care in America. In: Kohn LT, Corrigan JM, Donaldson MS, editors. To err is human: building a safer health system. Washington: National Academies Press; 2000.

2. Agency for Healthcare research and Quality. 2014. https://www.ahrq.gov/ sops/about/index.html. Accessed 2020 Jan 14.

3. Kirkman MA, Sevdalis N, Arora S, Baker P, Vincent C, Ahmed M. The outcomes of recent patient safety education interventions for trainee physicians and medical students: a systematic review. BMJ Open. 2015;5: e007705.

4. Woodhouse KD, Volz E, Bellerive M, Bergendahl HW, Gabriel PE, Maity A, et al. The implementation and assessment of a quality and safety culture education program in a large radiation oncology department. Pract Radiat Oncol. 2016;6:e127-34

5. Jones KJ, Skinner AM, High R, Reiter-Palmon R. A theory-driven, longitudinal evaluation of the impact of team training on safety culture in 24 hospitals. BMJ Qual Saf. 2013;22:394-404.

6. Boussat B, Seigneurin A, Giai J, Kamalanavin K, Labarère J, François P. Involvement in root cause analysis and patient safety culture among hospital care providers. J Patient Saf. 2017. https://doi.org/10.1097/PTS. 0000000000000456.

7. Wu Y, Fujita S, Seto K, Ito S, Matsumoto K, Huang CC, et al. The impact of nurse working hours on patient safety culture: a cross-national survey including Japan, the United States and Chinese Taiwan using the hospital survey on patient safety culture. BMC Health Serv Res. 2013;13:394.

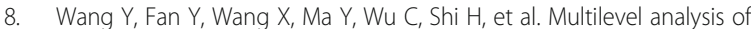
individual, organizational, and regional factors associated with patient safety culture: a cross-sectional study of maternal and child health institutions in China. J Patient Saf. 2019. https://doi.org/10.1097/PTS.0000000000000570.

9. Kong LN, Zhu WF, He S, Chen SZ, Yang L, Qi L, et al. Attitudes towards patient safety culture among postgraduate nursing students in China: a cross-sectional study. Nurse Educ Pract. 2019;38:1-6.

10. Eun-Mi C, So-Jung M, Won-Gyun C, Hie-Jin N. Relationships between dental hygienists' work environment and patient safety culture. BMC Health Serv Res. 2019;19(1):299.

11. Hall LH, Johnson J, Watt I, Tsipa A, O'Connor DB. Healthcare staff wellbeing, burnout, and patient safety: a systematic review. PLoS One. 2016;11: e0159015.

12. Welp A, Manser T. Integrating teamwork, clinician occupational well-being and patient safety-development of a conceptual framework based on a systematic review. BMC Health Serv Res. 2016;16:281.

13. Zhou P, Bai F, Tang HQ, Bai J, Li MQ, Xue D. Patient safety climate in general public hospitals in China: differences associated with department and job type based on a cross-sectional survey. BMJ Open. 2018;8:1-11.

14. Wagner A, Rieger MA, Manser T, Sturm H, Hardt J, Martus P, et al. Healthcare professional's perspectives on working conditions, leadership and safety climate: a cross-sectional study. BMC Health Serv Res. 2019;19:53.

15. Hannah KL, Schade CP, Lomely DR, Ruddick P, Bellamy GR. Hospital administrative staff vs. nursing staff responses to the AFRQ Hospital Survey on Patient Safety Culture. In: Henriksen K, Battles JB, Keyes MA, Grady ML, editors. Advances in patient safety. New directions and alternative 
approaches vol. 2. Rockville: Agency for Healthcare Research and Quality; 2008. p. 21-8.

16. e-stat. Survey of Medical Institutions. 2017. https://www.e-stat.go.jp/statsearch/database?page $=1 \&$ toukei $=00450021 \&$ tstat $=000001030908$. Accessed 2020 Jan 14.

17. Ito S, Seto K, Kigawa M, Fujita S, Hasegawa T, Hasegawa T. Development and applicability of hospital survey on patient safety culture (HSOPS) in Japan. BMC Health Serv Res. 2011;11:28.

18. Agency for Health Care Resarch \& Quality. Hospital survey on patient safety culture. 2019. https://www.ahrq.gov/sops/surveys/hospital/index.html. Accessed 2020 Jan 14

19. Øyane NM, Pallesen S, Moen BE, Akerstedt T, Bjorvatn B. Associations between night work and anxiety, depression, insomnia, sleepiness and fatigue in a sample of Norwegian nurses. PLoS One. 2013;8:e70228.

20. Carolyn SD, Desmond L, Sarah B, Lucy T. The relationship between physician burnout and quality of healthcare in terms of safety and acceptability: a systematic review. BMJ Open. 2017;7:1-14.

21. Ito S, Fujita S, Matsumoto K, Kitazawa T, Seto K, Hasegawa T. Factorial structure for the brief job stress questionnaire in Japanese health care workers. J Med Soc Toho. 2013;60:15-23.

22. Ito S, Fujita S, Seto K, Kitazawa T, Matsumoto K, Hasegawa T. Occupational stress among healthcare workers in Japan. IOS Press. 2014;49:225-34.

23. Burlison JD, Quillivan RR, Kath LM, Zhou Y, Courtney SC, Cheng C, et al. A multilevel analysis of U.S. hospital patient safety culture relationships with perceptions of voluntary event reporting. J Patient Saf. 2016. https://doi.org/ 10.1097/PTS.0000000000000336

24. Ammouri AA, Tailakh AK, Muliira JK, Geethakrishnan R, Al Kindi SN. Patient safety culture among nurses. Int Nurs Rev. 2014;62:102-10.

25. Evans SM, Berry JG, Smith BJ, Esterman A, Selim P, O'Shaughnessy J, et al. Attitudes and barriers to incident reporting: a collaborative hospital study. Qual Saf Health Care. 2006;15:39-43.

26. Schuerer DJ, Nast PA, Harris CB, Krauss MJ, Jones RM, Boyle WA, et al. A new safety event reporting system improves physician reporting in the surgical intensive care unit. J Am Coll Surg. 2006;202:881-7.

\section{Publisher's Note}

Springer Nature remains neutral with regard to jurisdictional claims in published maps and institutional affiliations.

Ready to submit your research? Choose BMC and benefit from:

- fast, convenient online submission

- thorough peer review by experienced researchers in your field

- rapid publication on acceptance

- support for research data, including large and complex data types

- gold Open Access which fosters wider collaboration and increased citations

- maximum visibility for your research: over $100 \mathrm{M}$ website views per year

At $\mathrm{BMC}$, research is always in progress.

Learn more biomedcentral.com/submissions 